\title{
Graduate Teaching Assistants' Views on Teaching ${ }^{1}$
}

\section{James M. Shaeffer}

University of Wyoming

\section{Lawrence T. McGill}

Total Research Corporation

\section{Robert J. Menges}

Northwestem University

How teachers learn their craft has been a perennial puzzle for educational research. Existing studies include numerous investigations of teachers beginning their careers in elementary and secondary settings (Veenman, 1984). Other research documents the career stages of university professors (Baldwin \& Blackburn, 1981; Blackburn, 1979; Cyntrynbaum, Lee, \& Wadner, 1982; Mathis, 1979; Ralph, 1973). Little is known, however, about graduate students as they begin work as teachers. This paper examines how Graduate Teaching Assistants (GTAs) view their early teaching experiences and interprets their views in light of recent research on teaching and professional socialization.

The position of teaching assistant has attracted criticism over the years. Berelson, for example, notes three shortcomings of the teaching assistantship: "(a) not all potential teachers have the experience [of being a teaching assistant]; (b) many have it far too long; and (c) the experience is insufficiently directed and planned" $(1960$, p.66).

But teaching is not the onlyjob for which newcomers are inadequately oriented and trained. In fact, Goffman contends that such inadequate orientation to new positions is the norm. 
When the individual [moves] into a new position in society and obtains a new part to perform, he is not likely to be told in full detail how to conduct himself, nor will the facts of his situation press sufficiently on him from the start to determine his conduct without his further giving thought to it. Ordinarily he will be given only a few cues, hints, and stage directions, and it will be assumed that he already has in his repertoire a large number of bits and pieces of performances that will be required in the new setting. (1959, pp. 72-3)

For both new teachers and their students, this lack of formal preparation is often detrimental to the learning experience. It is not surprising that "many TAs anticipate the semester with panic, wondering if they know enough to teach" (Boeher \& Sarkisian, 1985, p.9).

In the absence of formal preparation, GTAs must rely only on what they may have learned about teaching through informal means. This article examines four of these informal influences on GTAs' ideas about teaching: prior work experiences, recollections of role models, the feedback on teaching they currently receive, and their search for a comfortable teaching style.

Data for this study were obtained through interviews with 26 GTAs in seven departments at a midwestern research university. GTAs from departments of mathematics, chemistry, political science, English, sociology, philosophy, and economics talked at length about their views on teaching and learning. The interviews focused on: (a) GTAs' experiences prior to becoming a GTA; (b) how GTAs evaluate the success of a particular class session; and (c) GTAs' teaching styles. They were also asked to discuss what specifically impeded their effectiveness as teachers.

What GTAs told us in the interviews differed somewhat from our expectations about influences on their views of teaching. The results suggest that, at least for these GTAs: (a) the transferability of skills from other jobs and experiences is as important as role modeling; (b) student feedback during class is the most commonly used gauge of success (rather than, say, covering a designated amount of material during class); (c) GTAs are more concerned about the creation of "classroom comfort" than about the "tasks" of teaching; and (d) GTAs easily identify impediments to successful teaching, many of which they perceive as changeable and as within their control.

\section{Previous Experiences and Role Models}

Prior experience in situations related to teaching can significantly influence expectations and behavior as one begins work as a GTA. To the 
extent that teaching is simply a "job" like any other, then it is reasonable to expect that GTAs will call to mind situations from the past that are similar to the present teaching situation. They will transfer skills learned in past situations to the situation at hand. For example, Fink (1984) found that some new faculty rely on previous teaching experiences outside the "formal" classroom as guides to their current teaching. These experiences may include, for example, coaching or working in a museum.

In the absence of teaching models provided by formal training, beginning teachers also rely on their own previous exposures to teaching. It seems likely that GTAs would recall attributes of admired teachers from the past. Research attaches high importance to admired teachers, or "role models" (Bragg, 1976). In this view, GTAs learn primarily by identifying with and emulating teachers they have admired. Boehrer and Sarkisian (1985), for example, found that GTAs reported in interviews that they initially try to teach like professors they have admired. Beginning teachers also develop behavioral norms by recalling the kinds of teaching they experienced as students. Other information about appropriate teaching behaviors comes from fellow teaching assistants and from supervising instructors.

To determine how previous experiences affected their views of teaching, GTAs were asked: "Prior to your first experience as a teaching assistant at this university, did you have any other experiences, perhaps related to teaching, that you were able to draw upon in preparing to teach your first class here?" Responses show considerable diversity. As expected, some GTAs (about a third) drew upon previous service as an undergraduate and previous experience as a tutor.

Experience performing or talking to groups helped another quartcr of the group deal with teaching for the first time. One person had led small groups in seminary; another mentioned performing on stage; a third had been a member of a debate society. According to the GTAs, these activities helped them develop such transferable skills as "self-expression," "public speaking," and "learning to listen." For example, one pointed out that performing in a band or play gradually helped him to overcome his shyness; the confidence he gained as a performer was useful to him as a teacher.

Previous job-related experiences, including retail management, customer service, and editing, were mentioned by another quarter of the GTAs. Jobs like these are similar to teaching in certain respects. Both retail management and teaching require effective interpersonal skills. In customer service, it is often necessary to "reshape the way the customer 
thinks about the kind of service he's looking for," and editors must cultivate the art of commenting "tactfully" on another's work.

Two GTAs reported that they had "grown up in an academic environment," since their parents were teachers at one level or another. One said that counseling courses helped prepare him to deal with teaching.

Finally, both military and coaching experiences assisted several GTAs in their first-time teaching. Army veterans said they picked up skills from instructing subordinates. A tennis coach stated that helping people "image" successful performances was a technique he brought from the tennis court to the classroom.

Considering the thrust of the socialization literature, we expected that GTAs would talk about memorable teachers as role models when thinking about the kinds of experiences that helped prepare them for teaching. Rather surprisingly, only two GTAs mentioned particular teachers as influencing how they tackled their job of teaching.

This finding does not mean that role models are unimportant, since these results may be due, in part, to the way the question was phrased. But the fact that this question elicited many meaningful responses that did not refer to role models suggests that role models are but one of many socialization experiences that influence the approach GTAs take toward teaching.

\section{Current Feedback}

New teachers may also rely on immediate events as feedback on how well they are teaching. This feedback ranges from formal end-of-course evaluations to the reactions of students at a particular class session. Feedback from colleagues is also important, even if it is limited to informal conversations about what is working and what is not working in the classroom. Other indicators of how well things are going include the amount of material covered or whether a question was raised that the beginning teacher could not answer.

Literature on the socialization of new faculty into the teaching profession points towards the importance of student and colleague feedback in determining the strategies new teachers use. Leslie, Swiren, and Flexner (1977) suggest a relationship between the influences of feedback and of role models:

The acuity of the individual's perception [of his performance] is sharpened by the feedback received from role-clarifiers - role models, other faculty, peers, or student subordinates-when he tenuously "tries on" 
the professorial role. All of these clarifiers provide feedback that may either inhibit or support, i.e., reinforce, specific behaviors. The neophyte thus continually refines his observations of role models, differentiating, integrating, and generalizing from the cues provided him. (Leslie, Swiren, \& Flexner, 1977, pp. 129-130)

To learn what sources of feedback GTAs used, we asked them how they determine whether a particular class has been successful or unsuccessful. We expected responses such as covering material as planned, delivering material without getting stumped along the way, and quality of classroom discussion. But contrary to our expectations, most of the GTAs mentioned student participation and enthusiasm as the best indicator of classroom success or failure. This result held across disciplines; it was just as germane for math or chemistry GTAs as for those in English and political science.

Three of four math GTAs referred to immediate feedback from students as the most important indicator of success: "Student response is the most important thing"; "the way they are looking at you"; "whether students rush to get out when class is over"; "whether the questions they ask have been intelligent and show they have synthesized the material."

English and political science GTAs answered this question more elaborately, but finally drew the same conclusions. Eight of nine interviewees in these two departments gave primacy to student feedback in assessing the success of a particular class: "I would say that the blank look, the blank stare, is a pretty good gauge, an indication that the class has not been successful. Now if students are nodding vigorously or shaking their heads furiously, either of those reactions, I don't mind at all, because it means they will go and think about the issues raised in class"; "You could almost statistically show that the greater proportion of student participation and the less lecturing I've done, the more successful I thought the section was"; "The most important criterion is the enthusiasm that the students leave with, because a really successful class is the kind where I have to stop them from talking five minutes after the section is over, because I've got to go to my next section."

Such feedback from students and peers helps new GTAs to clarify their roles. As Rotem (1978) notes, learning any new skill depends upon perceptions of the consequences of one's performance:

Feedback on the results of performance may indicate to the learner how close his performance approaches a given standard and thus how much and in what direction he should change his behavior if he wishes to come closer to this standard. (Rotem, 1978, p. 305) 
The immediate consequences of one's performances are often the most persuasive. For new teachers, the most salient and immediate consequences of their teaching performance are the expressions on the faces of students during class.

\section{The Search for a Comfortable Style}

As one matures as a teacher, one also develops a style that balances individual dispositions with institutional demands. Granrose (1980) elucidates a set of fundamental skills (choosing, preparing, speaking, listening, responding, testing, grading) that form the basis of teaching and that "help create a teacher's style." But, according to Granrose, these skills "do not define style nor do they play the crucial part in developing a style" (1980, pp. 27-28). Style does not consist of piecing together a few techniques from here and some helpful hints from there; rather, style results from developing a certain "wholeness of character" that is reflected in an attitude of "love and respect" for one's students.

This "wholeness of character," Granrose goes on, is manifested in being "comfortable" as one teaches and in spreading this sense of comfort among students. Style at this general level must also accommodate the frustrations that come with the job, many of which (for example, underprepared students and too little time) are outside the control of the GTA. Where a teacher is in this process of developing a style will certainly influence the views she or he holds about teaching.

For many GTAs, our interview was the first opportunity they had ever taken to reflect on their own teaching styles. Some had little to say, but after a bit of coaxing (for example, after prompts such as "Can you think of any adjectives that might describe your teaching style?"), most were able to settle on at least a two- or three-word description.

Many GTAs characterized their style, at least in part, as either "humorous" or "relaxed." These two strategies are conducive to the development of a sense of "comfort" in the classroom, recalling Granrose (1980). But some characterized their styles quite differently. Two mentioned "cajoling students to engage in discussion," which, although hardly comfort-making, could arguably be considered student-centered. Two others were unable to describe a teaching style for themselves, commenting, "I really haven't ever thought about it."

In general, GTAs' conversations about style suggest that most of them are aware of using style to shape a desired classroom atmosphere. In particular, they seem to be less concerned with completing specific tasks 
of teaching than with creating a "comfortable" climate in which to interact with students.

The fact that GTAs' views of style are rather general does not mean that specific concerns are absent. GTAs were asked to identify and rate impediments to their teaching on three dimensions derived from attribution theory (Weiner, 1976; Weiner, 1979): whether the GTA felt he or she had control over the impediment; whether the impediment was easy or hard to change; and whether it was likely or unlikely to change. Interviewees mentioned 19 different impediments to their effectiveness as teachers, and only two said that nothing impeded their effectiveness as teachers. As a math GTA said, "I'm doing as well now [as a teacher] as I ever will."

Of the 19 impediments mentioned, lack of time was mentioned most often. Lack of time meant "not having enough time for class preparation" and "a lack of time to do my own class work and the work necessary for teaching." Most GTAs viewed lack of time as outside their control and as both difficult and unlikely to change. For some GTAs, having ample time was vital to being both a good graduate student and an effective teacher.

Lack of knowledge of subject matter was the impediment mentioned next most often. By and large, GTAs indicated that a better understanding of the subject matter would improve their teaching. Lack of knowledge was viewed as a factor that was under their control and both easy and likely to change.

Lack of experience as a teacher was mentioned by three GTAs in the English department and by one from math. They said that they felt their experience level was going to change, although it was something they did not control (for a complete list of impediments, see McGill, Shaeffer, \& Menges, 1988).

These comments can be compared with responses by professors in two previous studies by Geis and Smith $(1979 ; 1980)$. These researchers suggest that the apparent lack of interest among faculty members in attending workshops or seminars about teaching may be due to how they view the causes of classroom events. In interviews with professors, they asked what factors or variables limited teaching effectiveness and also asked for attributional data.

Most of the factors the professors mentioned were perceived as out of their control and unlikely to change. For example, they mentioned such factors as late time slots, unresponsive students, reduced admissions standards, ill-prepared students, shape of the room, students' obsession with grades, and students' enthusiasm for the subject. 
Attribution theory predicts that because these factors are perceived as beyond the faculty member's control and unlikely to change, faculty members will not take time or effort to try to alter them. Teachers with these perceptions would feel no need to attend workshops or seminars on faculty development, since they expect that nothing they might learn would change the situation.

Both professors and GTAs were most concerned with the lack of time for teaching and research, a factor they regarded as out of their control. In fact, for professors, the most frequently mentioned impediments were seen as out of their control and unlikely to change. Although GTAs regarded some impediments similarly, nearly half of the impediments mentioned by GTAs were considered as under their control and likely to change.

\section{Implications for GTA Development}

These GTAs display genuine concern for students' learning, but they also feel unable to do as good a job of teaching as they would like. These findings require replication, since they are based on a single-institution sample. Nevertheless, we offer some tentative implications for intervention and guidance strategies that build upon GTAs' recognition that their teaching might be more successful.

First, to the extent that GTAs draw upon past experiences in coming to grips with teaching for the first time, it is important that supervisors, counselors, and others recognize connections between teaching and previous experiences. A formal analysis of "transferability," in the sense that this term is used in research on learning (Gagnè, 1974), may be a useful exercise. If aspects of previous experience most likely to transfer to teaching are made explicit, new GTAs can approach their responsibilities with some assurance that they already possess some of the skills needed to do an effective job.

Second, since learning is contingent upon feedback from "role clarifiers," it is important to realize that for beginning teachers, role clarifiers include not only role models, but other faculty, peers, and, as we have found, student subordinates. Additionally, learning any new skill depends upon one's perception of the consequences of one's performance. For new teachers, the clearest and most immediate consequences of performance are the expressions on the faces of students during class. Those who provide guidance for GTAs, however, may wish to emphasize additional indicators of classroom success, some of which are less imme- 
diate. These indicators include test scores, end- of-term evaluations, and so on.

Third, GTAs can be made aware of the potential impact of particular styles upon classroom atmosphere. Many of these GTAs sought to cultivate a relatively informal, comfortable style. Jeremy Bentham is quoted by Granrose as saying that "the way to be comfortable is to make others comfortable, the way to make others comfortable is to appear to love them, and the way to appear to love them is to love them in reality. Something like this is a necessary part of the best teaching" $(1980$, p. 29). To the extent that this is true, it is important to cultivate styles that foster comfort in the classroom.

Fourth, the graduate teaching assistantship experience appears to be a time in which one's philosophy and approach to teaching are tentative. The potential for successful intervention is great. For example, data about GTAs' theories of teaching might be gathered and fed back to them as the basis for reflection and discussion (Menges \& Rando, 1989). Given the usual lack of formal training of GTAs during this time of uncertainty about values, assumptions, and techniques, it appears that significant opportunities for guidance are being lost.

Fifth, an overriding frustration about teaching is lack of time. This lack of time may in fact be the major impediment preventing GTAs from attending seminars about teaching. They may be no more likely than professors to attend, unless it can be shown that the seminars will help them become more efficient.

Sixth, a number of impediments to teaching were rated as controllable and easy to change. Programs for GTAs are well advised to direct their energies towards these areas. Other impediments were rated as uncontrollable and hard to change. Seminars aimed at understanding how such perceptions develop may help GTAs see the impediments as more controllable and changeable.

Finally, because interviews stimulate reflection about one's attitudes, values, and behaviors, the interviewing process itself should be recognized as an intervention (McGill \& Shaeffer, 1986). Using interviews to document GTAs' perceived impediments to teaching provides useful information for program planning and further demonstrates concern for GTAs and their teaching. 


\section{Notes}

${ }^{1}$ Portions of this study were presented at the Tenth International Conference on Improving University Teaching, University of Maryland, 1984.

\section{References}

Baldwin, R., \& Blackburn, R. (1981). The academic career as a developmental process: Implications for higher education. Joumal of Higher Education, 52, 598-614.

Berelson, B. (1960). Graduate education in the United States. New York: McGraw-Hill.

Blackburn, R. (1979). Academic careers: Pattems and possibilities. Current Issues in Higher Education, No. 2, Washington, DC: American Association for Higher Education.

Boehrer, J., \& Sarkisian, E. (1985). The teaching assistant's point of view. New Directions for Teaching and Learning 22, 7-20.

Bragg, A. (1976). The socialization process in higher education. Washington, DC: ERIC/AAHE Research Report *7.

Cyntrynbaum, C., Lee, S., \& Wadner, D. (1982). Faculty development through the life course. Joumal of Instructional Development, 5, 11-22.

Eble, K. (1983). The aims of college teaching. San Francisco, CA: Jossey-Bass.

Fink, L.D. (1984). The first year of college teaching. New Directions for Teaching and Learning, 17.

Gagnè, R. (1974). Essentials of learning for instruction. New York: Holt, Rinehart, and Winston.

Garland, T. (1983). A training program for graduate TAs: The experiences of one department. Teaching Sociology, 10, 487-504.

Geis, G.L., \& Smith, R. (1979). Professors' perceptions of teaching and learning: Implications for faculty development. Paper presented at the Meeting of the American Educational Research Association, San Francisco, CA.

Goffman, E. (1959). The presentation of self in everyday life. New York: Doubleday.

Granrose, J. (1980). Conscious teaching: Helping assistants develop teaching styles. New Directions for Teaching and Leaming 1, 21-31.

Leslie, L., Swiren, J., and Flexner, H. (1977). Faculty socialization and instructional productivity. Research in Higher Education, 7, 127-143.

Mathis, B.C. (1979). Academic careers and adult development: A nexus for research. Current Issues in Higher Education, No. 2, Washington, DC: American Association for Higher Education.

McGill, L.T., Shaeffer, J.M., \& Menges, R.J. (1988). Windows of opportunity: How to intervene successfully in the development of graduate teaching assistants. In E.C. Wadsworth (Ed.), Professional and organizational development in higher education: $A$ handbook for new practitioners (pp. 121-126). The Professional and Organizational Development Network in Higher Education. 
McGill, L.T., \& Shaeffer, J.M. (1986). Using interviews in development programs for beginning teachers. In M.D. Svinicki (Ed.), To Improve the Academy, 5, 103-110.

Menges, R.J., and Rando, W.C. (1989). Improving graduate teaching assistants' instruction through attention to their implicit theories of teaching. College Teaching, in press.

Overall, J.U. IV, \& Marsh, H.W. (1982, December). Students' evaluations of teaching: An update. AAHE Bulletin, pp. 9-13.

Ralph, N. (1973). Stages of faculty development. New Directions for Higher Education, 1, 61-68.

Rotem, A. (1978). Effects of feedback from students to university instructors: An experimental study. Research in Higher Education, 9, 303-318.

Smith, R., \& Geis, G.L. (1980). Professors' views of teaching and improvement. Paper presented at the CSSE Meetings, Montreal.

Weiner, B. (1976). An attributional approach for educational psychology. Review of Research in Education, 4, 199-209.

Weiner, B. (1979). A theory of motivation for some classroom experiences. Journal of Educational Psychology, 71, 2-25.

Veenman, S. (1984). Perceived problems of beginning teachers. Review of Educational Research, 54, 143-178. 